\title{
Taxonomy, Phylogeny, Cultivation and Biological Activities of a Lentinus species from Andaman \& Nicobar Islands (India)
}

\author{
Ved Parkash Sharma, Shwet Kamal*, Ramesh Chandra Upadhyay, Satish Kumar, Sanjeev Kumar Sanyal, \\ Manjit Singh
}

ICAR-Directorate of Mushroom Research, Chambaghat, Solan, (HP) - 173213, India

\section{A B S T R A C T}

\begin{abstract}
Fruit bodies of Lentinus were collected from subtropical climate of Andaman \& Nicobar Islands (India). Pure culture was prepared by tissue culture on Malt-extract-agar (MEA) medium at $25 \pm 2{ }^{\circ} \mathrm{C}$. The specimen was studied for its identification, taxonomy and phylogeny and identified as Lentinus sajor-caju by morphological and microscopical studies. The identification was confirmed through ITS $5.8 S$ rDNA sequencing and sequence analysis. Its cultivation was done on saw dust and wheat bran. The fruit bodies were obtained at a temperature of $28 \pm 2{ }^{\circ} \mathrm{C}$ and $80-85 \% \mathrm{RH}$. The cultivated Lentinus sajor-caju fruit bodies were analysed for nutritional and biological properties and observed that the cultivated mushroom has good nutritional properties and antioxidant, reducing and DPPH free radical scavenging properties are comparable to commercially cultivated Lentinula edodes strains.
\end{abstract}

Keywords: Mushroom; Lentinus sajor-caju; Taxonomy; Phylogeny; Cultivation; Nutrition

\section{INTRODUCTION}

Species of Lentinus are normally wood-decaying basidiomycetes and have decurrent lamellae, dimitic tissues in the basidiome, and hyaline, ellipsoid to cylindric spores. Species in the subgenus Lentinus have hyphal pegs (Corner 1981; Pegler 1983). Generally, the basidiomes are xeromorphic with a tough, firm texture when dry and have a long life span. Traditionally, Lentinus has been placed in the agaric family Tricholomataceae because species possess a lamellate hymenophore and white spore print (Miller, 1973). A close relationship has long been suspected between Lentinus and certain polypores (Comer, 1981; Pegler, 1983; Singer, 1986). The limits of Lentinus, Panus Fr.. and Pleurotus (Fr.) Qukl are controversial. The works by Comer (1981), Kuhner (1980), Pegler (1975. 1983), and Singer (1986) all differ significantly in their treatment of these genera.

In the present study, Lentinus fruit bodies were collected from Havlock Islands (Krishna Nagar) Andaman and Nicobar Island (India). The specimen was collected during
December 2009 at a geographical location of Latitude: $12^{\circ} 01^{\prime} \mathrm{N}$; Longitude: $092^{\circ} 98^{\prime} \mathrm{E}$ and temperature of $25-28^{\circ} \mathrm{C}$. The specimen was taxonomically identified on the basis of morphology as Lentinus species. The detailed study of the specimen was undertaken considering a Lentinus sp. growing at a higher temperature. During the study, identification and phyologenetic position of the specimen at morphological and molecular level was done. Further successful cultivation method at experimental level was tried along with the proximate nutritional analysis and its antioxidant properties.

\section{MATERIAL AND METHODS}

\section{Specimen collection and morphology}

The fungal material along with some dead wood was removed from the host and packed in paper envelopes. Field notes such as date of collection, locality and forest type were noted. Photographs of fresh specimens were taken as colour and texture of basidiocarps may change on drying (Fig.1). Reaction of different fungal structures

\footnotetext{
*Corresponding author:

Shwet Kamal, Directorate of Mushroom Research (Indian Council of Agricultural Research) Chambaghat, Solan (HP) - 173213, India. Phone: +91 1792 230767, Fax: +91 1792 231207, E-mail: shwetkamall@gmail.com
} 
i.e. hyphae, basidia, basidiospores and sterile structures with reagents like cotton blue, Melzer's reagent and Sulphovanillin was checked. Spore prints were taken by placing fresh specimen with its hymenial surface facing toward the glass slide which is placed on a piece of black chart paper. After 24 hours spore prints were checked and packed in butter paper envelopes. The collected specimens were dried and packed in paper envelope.

\section{Microscopic studies}

The collection was examined for microscopic details concerning the type and arrangement of hyphae, basidia, basidiospores and sterile structure, at different magnifications of compound microscope by making crush mounts or hand cut sections in water and 3\% $\mathrm{KOH}$. These were stained in 1\% Cotton blue (in Lactophenol), $1 \%$ Congo red in distilled water, $1 \%$ Phloxine in distilled water, Melzer's reagent and Sulphovanillin. Camera lucida drawings of the microscopic structures were made on white paper sheets. Microphotographs of interesting structures were also taken. Magnification lines for all the diagrams were given. All the observations made were compiled in form of description and compared with the published literature. After the microscopic studies, the samples were stored as a herbarium having necessary data and herbarium number.

\section{Culture preparation}

Pure culture was prepared by tissue culture after the sterilization of fruit body with alcohol. Small tissue from the cap portion was transferred to sterile Malt-extract-agar (MEA) culture slants. These slants are then incubated at $25 \pm 2{ }^{\circ} \mathrm{C}$ for 2 weeks to obtain pure culture.

\section{DNA extraction}

For DNA extraction, mycelial biomass was grown stationary in $150 \mathrm{~mL}$ conical flasks containing $50 \mathrm{~mL}$ of liquid culture medium (malt extract, $10 \mathrm{~g} \mathrm{l}^{-1}$; glucose, $5 \mathrm{~g} \mathrm{l}^{-1}$ ) for 7 days at $25 \pm 1{ }^{\circ} \mathrm{C}$ in darkness. Total genomic DNA was isolated from $100 \mathrm{mg}$ of dried mycelium using DNeasy plant minikit following the manufacturer's (Qiagen Ltd.) instructions. DNA was eluted by $100 \mu \mathrm{L}$ of elution buffer (Qiagen). The DNA was quantified using the DNA flurometer (DyNA quant 200, Amarsham Biosciences). The equipment was calibrated using calf thymus DNA as the standard.

\section{Amplification of ITS 5.8S rDNA region}

The Polymerase Chain Reaction (PCR) primer ITS-1 (5'-TCC GTA GGT GAA CCT GCG G-3') and ITS-4 (5'-TCC TCC GCT TAT TGA TAT GC-3') developed by White et al. (1990) were used to amplify the ITS of ribosomal DNA, which encompasses the $5.8 \mathrm{~S}$ gene and both ITS-1 and ITS-2 regions. Amplification by PCR was performed in a total volume of $50 \mu$ l containing: 10x PCR buffer, $5 \mu \mathrm{l}(100 \mathrm{mM}$, Tris - $\mathrm{HCl}, \mathrm{pH} 8.3,15 \mathrm{mM} \mathrm{MgCl}$, $250 \mathrm{mM} \mathrm{KCl}$ ), $1 \mathrm{U}$ Taq DNA polymerase (Promega), $160 \mu \mathrm{M}$ dNTP mix (MBI, Fermentas), 50 pmol of each ITS-1 and ITS-4 primers, 50 ng genomic DNA in dH2O. Two drops of mineral oil (Sigma Chem) were added before PCR. The reactions were performed in a Master cycler (MJ Research, USA model-PTC100) with following conditions. 1 min denaturation at $95^{\circ} \mathrm{C}, 30 \mathrm{sec}$ annealing at $50{ }^{\circ} \mathrm{C}, 1 \mathrm{~min} 20 \mathrm{sec}$ elongation at $72{ }^{\circ} \mathrm{C}$, for 34 cycles with a final elongation step of $72{ }^{\circ} \mathrm{C}$ for $10 \mathrm{~min}$.

The PCR products were visualized on $1 \%$ agarose gel in Tris-Acetic acid-EDTA (1x TAE) buffer at $80 \mathrm{~V}$ for $60 \mathrm{~min}$. Agarose gels were stained with ethidium bromide and photographed under UV light for amplified ITS products.

\section{Sequencing of ITS 5.8S rDNA region}

The PCR-amplified ITS region was sequenced using Big Dye Terminator V 3.1. Cycle Sequencing kit (ABI, Foster City, California, USA) and analyzed on an ABI Prsim R 3700 DNA Analyzer (ABI). The sequence data obtained from the ITS-4 reverse primer was inversed using Genedoc (Software) and complemented with ITS-1 sequences to obtain complete ITS sequences. Nucleotide sequence comparisons were performed by the basic local alignment search tool (BLAST) network services against the National Centre for Biotechnology Information (NCBI) database. The mushroom species were designated to the sequenced cultures and analyzed based on similarity with the bestaligned sequence of BLAST search. The alignments and tree were submitted to Treebase databases and the url is http://purl.org/phylo/treebase/phylows/study/ TB2:S15753. 5.8S rRNA gene sequence alignments were performed using Clustal X 1.83 software (Thompson et al., 1997). Phylogenetic analysis of the sequence was done using closest sequence found in the NCBI database using BLAST pairwise alignment using fast minimum evolution method.

\section{Cultivation}

Mushroom spawn was prepared on wheat grains by following standard procedure of spawn production. Cultivation was carried out on mixed saw dust collected from broad leave trees. Fifty $\mathrm{kg}$ saw dust was soaked in 70 litre of water for 18 hours (Moisture 58-60\%). Sodium bicarbonate $150 \mathrm{~g}$, calcium carbonate $500 \mathrm{~g}$ and $2 \mathrm{~kg}$ wheat bran was mixed on the next day. After through mixing $2 \mathrm{~kg}$ wet substrate was filled in each polypropylene bag. The bags were sterilized in autoclave at $22 \mathrm{lbs}$ for 2 hours. On cooling the bags were inoculated with $50 \mathrm{~g}$ spawn in laminar flow. The inoculated bags were incubated in cropping room at $25-26^{\circ} \mathrm{C}$ temperatures for spawn run. When the bags were fully colonized, the polythene cover was 
removed and bags were sprayed twice to maintain $80-85 \%$ $\mathrm{RH}$. Two temperature treatments were used $25 \pm 1^{\circ} \mathrm{C}$ and $28 \pm 2^{\circ} \mathrm{C}$. Diffused light for 4 hours was provided during the cultivation trial.

\section{Nutritional analysis}

The mushroom samples were oven dried at $45^{\circ} \mathrm{C}$ for $24 \mathrm{hrs}$ and packed in the polythene packs. The method for protein analysis adapted was IS 7219: 1973 (RA 2005), protein and fats were analysed using standard protocols PBTI/SOP/18/TP-11, sodium was analyzed using AOAC 999.10 protocols while Iron, copper, magnesium, selenium, zinc, potassium and manganese were estimated using AOAC 999.10 protocol of ICP-MS. The analysis was got done at Punjab Biotechnology Incubator, Mohali, Punjab (India).

\section{Antioxidant assay}

Five gram of dried powder of the mushroom was taken in a screw cap bottle and extracted with $100 \mathrm{ml}$ of methanol for 24 hrs on a shaker and Filtered through Whatman no. 1 filter paper. Repeated the extraction twice and concentrated the extract under vacuum. Ferric Thiocyanate (FTC) method was used to estimate the antioxidant activity of the sample. Four $\mathrm{ml}$ of sample was taken in a screw cap tube with $4.1 \mathrm{ml}$ of $2.5 \%$ of linoleic acid and $8.0 \mathrm{ml}$ of $0.05 \mathrm{M}$ Phosphate buffer $\mathrm{pH}-7$ and $3.9 \mathrm{ml}$ of water and placed in oven at $40^{\circ} \mathrm{C}$ in dark for $24 \mathrm{hr} .9 .7 \mathrm{ml}$ of $75 \%$ ethanol and $0.1 \mathrm{ml}$ of $30 \%$ ammonium thiocynate was added to $0.1 \mathrm{ml}$ of this mixture in a test tube. Incubated for 3 minutes and $0.1 \mathrm{ml}$ of $0.02 \mathrm{M} \mathrm{FeCl}_{2}$ was added. Absorption was read at $500 \mathrm{~nm}$ against a control.

\section{Reducing activity}

The reducing activity of extract was determined according to the method of Oyaizu (1986). Mixed $1 \mathrm{ml}$ of extract $(1 \mathrm{mg} / \mathrm{ml}$ in distilled water) with $2.5 \mathrm{ml}$ phosphate buffer (0.2 M, pH 6.6) and $2.5 \mathrm{ml}(1 \%)$ potassium ferricyanide $\left[\mathrm{K}_{3} \mathrm{Fe}(\mathrm{CN})_{6}\right]$ and incubated at $50^{\circ} \mathrm{C}$ for $20 \mathrm{~min}$. Added $2.5 \mathrm{ml}$ of $(10 \%)$ trichloroacetic acid to the mixture and centrifuged at $3000 \mathrm{rpm}$ for $10 \mathrm{~min}$. Took $2.5 \mathrm{ml}$ of upper layer and mixed with $2.5 \mathrm{ml}$ distilled water and $0.5 \mathrm{ml}(0.1 \%)$ $\mathrm{FeC}_{3}$ and measure the absorbance at $700 \mathrm{~nm}$.

\section{Scavenging effect on DPPH radical}

The effect of extract on DPPH (2,2-Diphenyl-1Picrylhydrazyl) radical was estimated according to the method of Hatano et al. (1988). Four $\mathrm{ml}$ of extract $(0.05 \mathrm{mg} / \mathrm{ml}$ in distilled water) was mixed with $1 \mathrm{ml}$ methanolic solution of DPPH $(1 \mathrm{mM})$. The mixture was shaken and left to stand at room temperature for $30 \mathrm{~min}$; the absorbance of the resulting solution was measured spectrophotometrically at 517 . A low value of absorbance shows the more scavenging of free radical.

\section{RESULTS}

\section{Taxonomic studies}

Basidiomes were very small, pileate, with surface greyish white when fresh to grayish orange on drying. Pileus was thin, convex, coriaceous, umbilicate to infundibuliform; margin inflexed, entire, thin at first reflexed, involute at maturity; dry, uniformly velutinous to slightly long-hispid or subsquamulose furfuraceous, zonate, densely ciliate; hairs dark brown. Lamellae arcuate, deeply decurrent, grayish orange with entire margin. Stipe central, excentric, rarely lateral, cylindrical, slender, solid, yellowish brown, uniformly and persistently velutinous, with dark brown hairs. Hyphal system dimitic; generative hyphae up to $4.5 \mu \mathrm{m}$ wide, branched, septate, with clamps, thin- to thickwalled, hyline with some oily contents. Skeletal hyphae up to $7.0 \mu \mathrm{m}$, hyaline with a thickened wall, unbranched or with an occasional short, lateral branch, either terminal or intercalary in origin. Basidia were 12.5-16.2 × 3.5-4.5 $\mu \mathrm{m}$ in size, clavate, 4-sterigmate, with basal clamp; sterigmata up to $2.5 \mu \mathrm{m}$ long. Basidiospores were 5.5-7.5 $\times 2.5-2.8 \mu \mathrm{m}$ in size, narrowly ellipsoid to cylindrical, with oil droplets, inamyloid, acyanophilous (Fig. 2).

\section{Phylogenetic studies}

The amplified ITS region comprising ITS-1, 5.8S rRNA gene, and ITS- 2 of the accession was between 550 and $600 \mathrm{bp}$. The results of sequencing using ITS- 1 and ITS- 4 primers and its BLAST analysis against NCBI database showed $99 \%$ identity with $99 \%$ query sequence cover with L. sajor-caju isolate NCBI accession GU207309.1. The expect value of the BLAST was also found to be 0.0 , which conform the identity of the specimens as L. sajor-caju (Fig.3).

The Phylogenetic analysis was done using NCBI phylogentic tools using fast minimum evolution method. The results

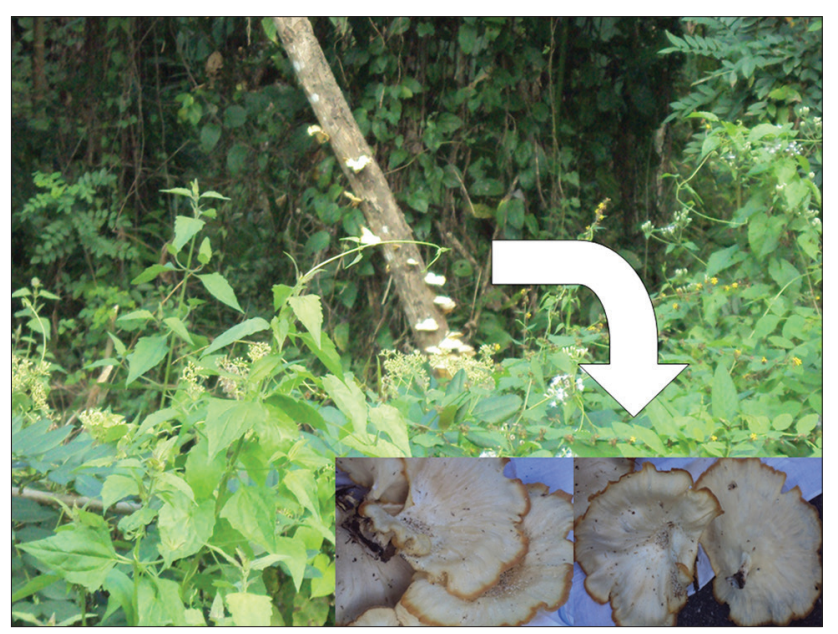

Fig 1. Lentinus sajor-caju in its natural habitat at Havlock islands, Andaman (India). 


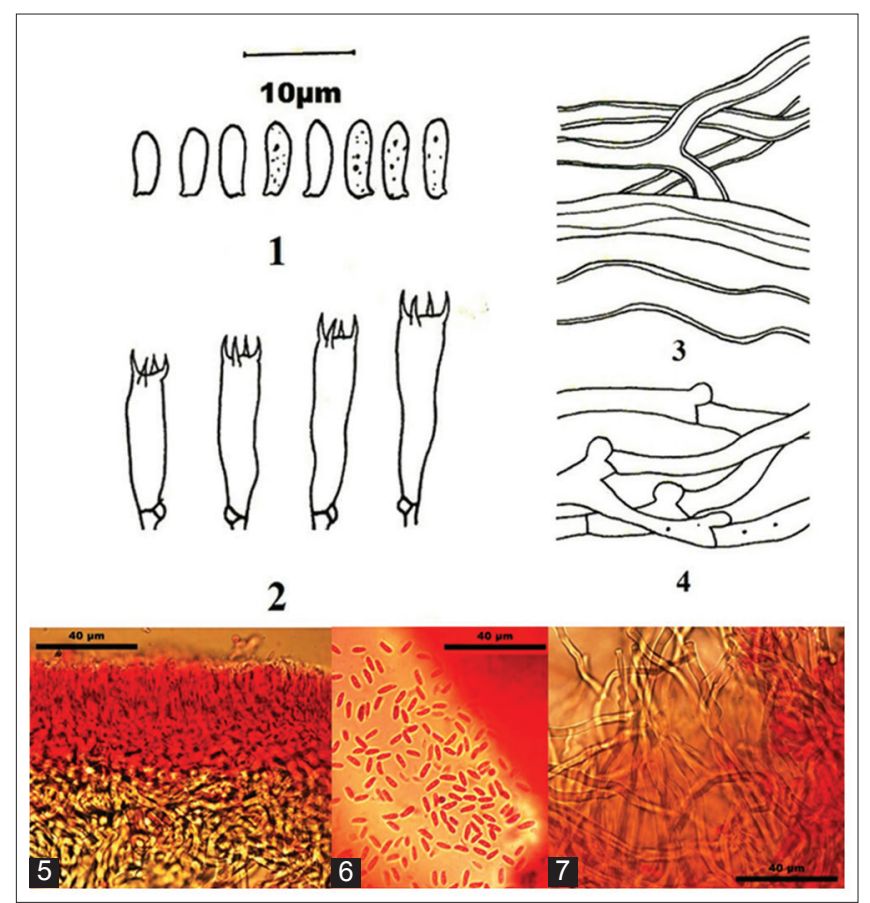

Fig 2. Camera lucida drawing of basidiospores (1), basidia (2), dimitic hyphal system \& clamp connections in the hyphae $(3,4)$; Microphotograph of dimitic hyphal system (5), basidiospores (6) and skeletal hyphal system (7). also showed the minimum distance with L. sajor-caju strains. The subject sequence also showed nearly $95-97 \%$ similarity with L. polychrous, L. striatulus and L. scleropus (Fig.4).

\section{Cultivation}

In the cultivation trials two temperatures were tried for fruiting of the mushroom. No fruiting was obtained even after 60 days of opening the bags at $25+1{ }^{\circ} \mathrm{C}$. Thereafter the blocks were shifted to another room where $28-30^{\circ} \mathrm{C}$ temperature and $\mathrm{RH} 80-85 \%$ were maintained. Light was also provided for 4 hours daily. Primordia start developing after 12 days, which fully develop in the next 3-4 days (Fig. $5 \mathrm{a} \& \mathrm{~b}$ ). The next flush appeared after 20 days. The average weight of the fresh fruit body was $17 \mathrm{~g}$. The fruit bodies were characterized with a distinct annulus near base (Fig. 5a).

\section{Nutritional analysis}

The nutritional analysis of the cultivated L. sajor-caju mushroom was done through Punjab biotechnology incubator, Mohali (Punjab). The laboratory is notified agency for analysis of food products. The results are given in the Table.1. The nutritional profile of the cultivated mushroom is compared with that of wild $L$. sajor-caju, which

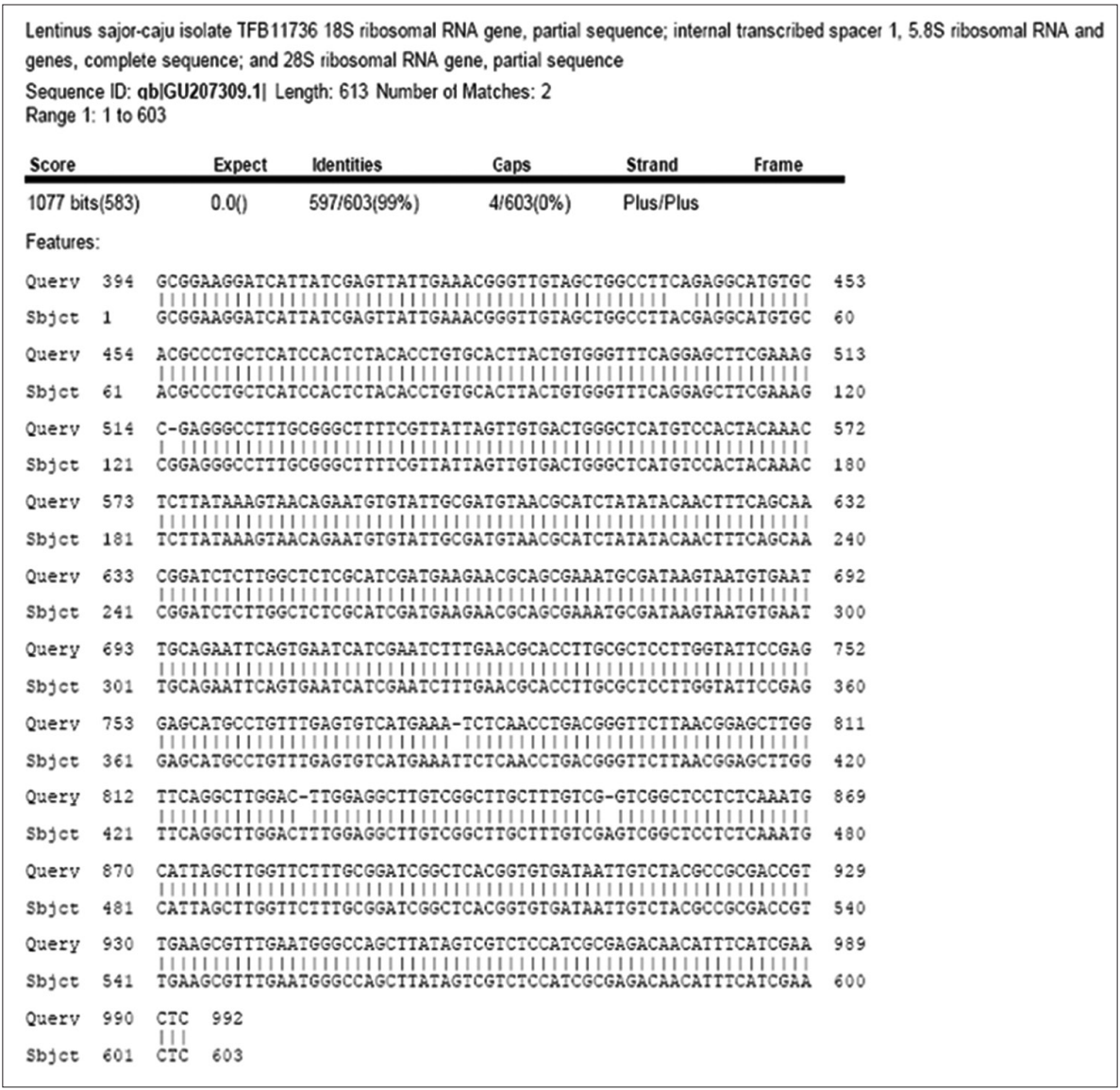

Fig 3. BLAST results against NCBI, USA website showing $99 \%$ similarity with expect value 0.0 . 
Table 1: Proximate analysis of cultivated Lentinus sajor-caju vis-à-vis wild mushroom on dry wt basis

\begin{tabular}{|c|c|c|c|c|c|}
\hline Parameter & Cultivated & Wild* & Parameter & Cultivated & Wild* $^{*}$ \\
\hline Protein (\%) & 12.56 & 1.050 & Copper $(\mathrm{mg} / \mathrm{kg})$ & 10.62 & 13.3 \\
\hline Carbohydrate (\%) & 74.38 & 85.82 & Magnesium (\%) & 0.130 & 1.02 \\
\hline Fat $(\%)$ & 1.18 & 0.80 & Zinc $(\mathrm{mg} / \mathrm{kg})$ & 2.79 & 40.00 \\
\hline Sodium (mg/100 g) & 104.46 & 0.726 & Potassium (mg/100 g) & 1170 & 0.0274 \\
\hline Iron (mg/kg) & 230.03 & 140.00 & Manganese $(\mathrm{mg} / \mathrm{kg})$ & 8.56 & - \\
\hline
\end{tabular}

${ }^{*}$ Gulati et al. (2011)

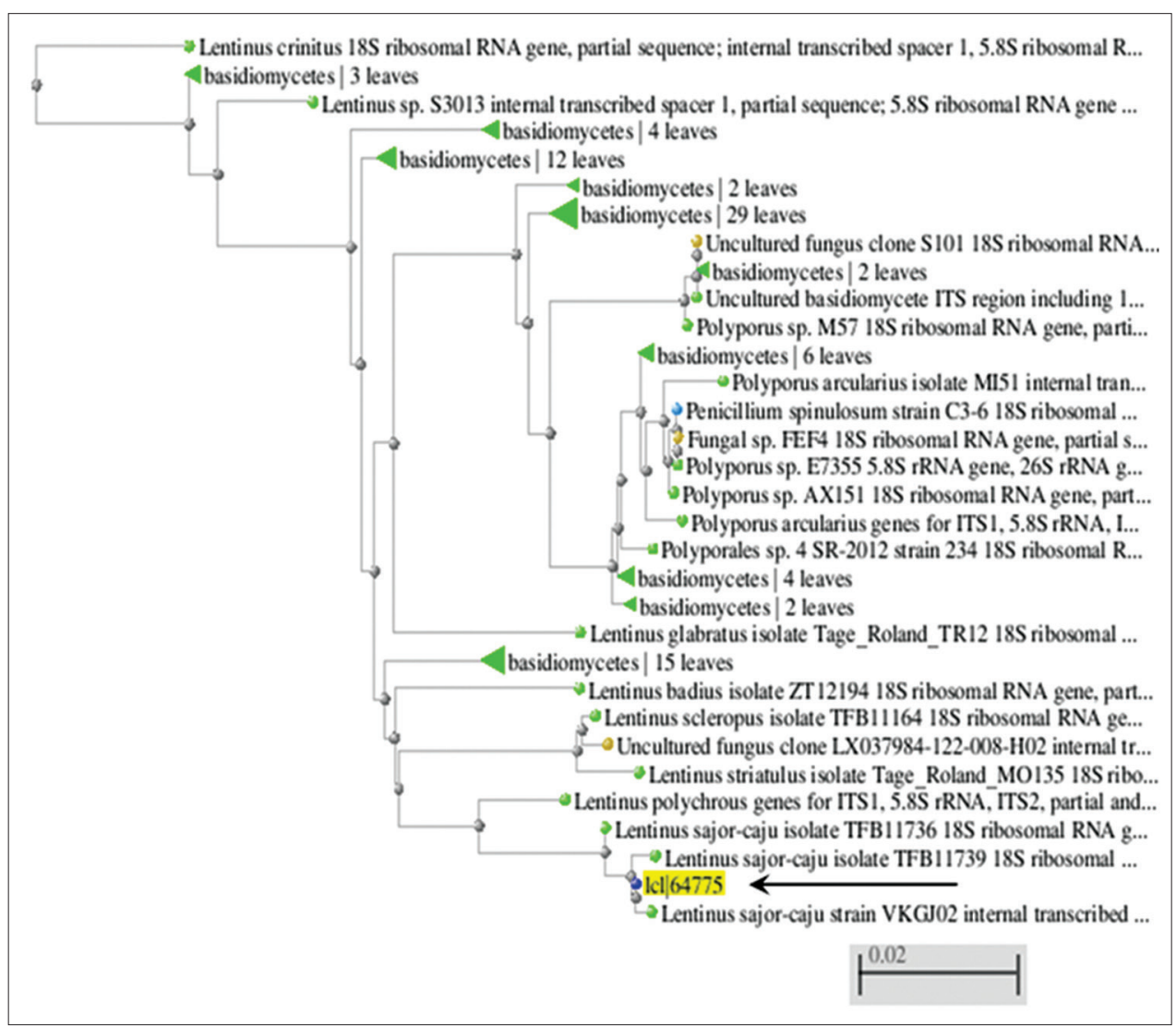

Fig 4. The distance tree based on ITS-5.8S sequences of Lentinus sajor-caju using fast minimum evolution method showing distance with different Lentinus species.

was reported by Gulati et al. (2011). The values in these two cases are not matching and are particularly at variance for protein, sodium, potassium and zinc contents.

\section{Nutraceutical properties}

The collected and cultivated strain of L. sajor-caju was analysed for their netraceutical properties in respect of antioxidant property, reducing activity and DPPH radical scavenging activity along with some other cultivated strain of Lentinula edodes. The assays were done on the mushroom cultivated on saw dust. The maximum antioxidant property was recorded in strain OE-9 (62.28\%) of Lentinula edodes mushroom (Fig. 6) while all the other strains of L. edodes mushroom showed statistically at par antioxidant activity with $L$. sajor-caju. In respect of reducing properties OE-16 strain of $L$. edodes strain showed maximum reducing activity when potassium ferrycyanide was used as substrate while all the other strains of L. edodes and L. sajor-caju has showed statistically at par activity. OE-18 strain of L. edodes showed maximum DPPH free radical scavenging property followed by OE-19 strain. The cultivated L. sajor-caju strain (X-1121) has shown fairly good DPPH free radical scavenging property while some of the $L$. edodes strains showed low activities.

\section{DISCUSSION}

The species L. sajor-caju was earlier considered to be a synonym to $P$. sajor-caju but confusion on its taxonomic position and scientific name have occurred since it was first isolated for cultivation. In order to distinguish these two species and to clarify their taxonomic position, linedrawings illustrating macro-and microscopic features and 


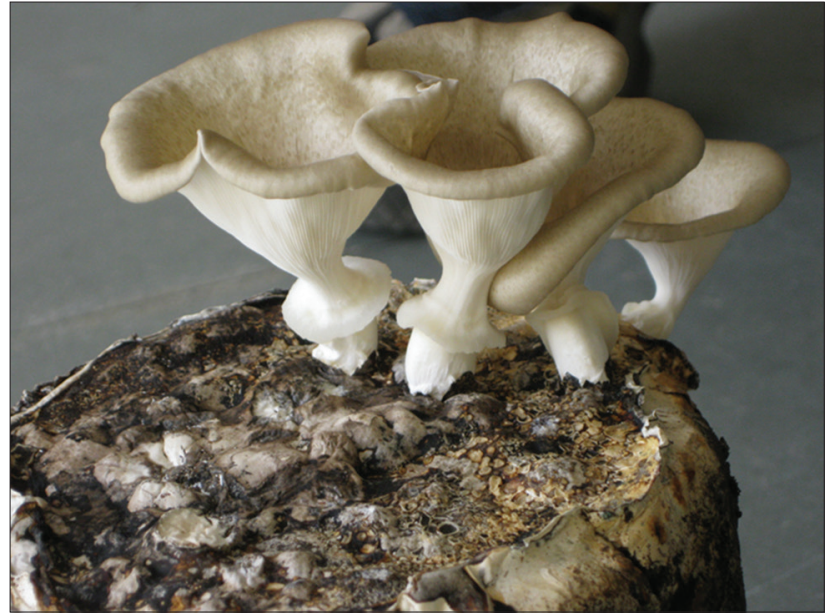

Fig 5a. Developing fruit bodies (with annulus near base).

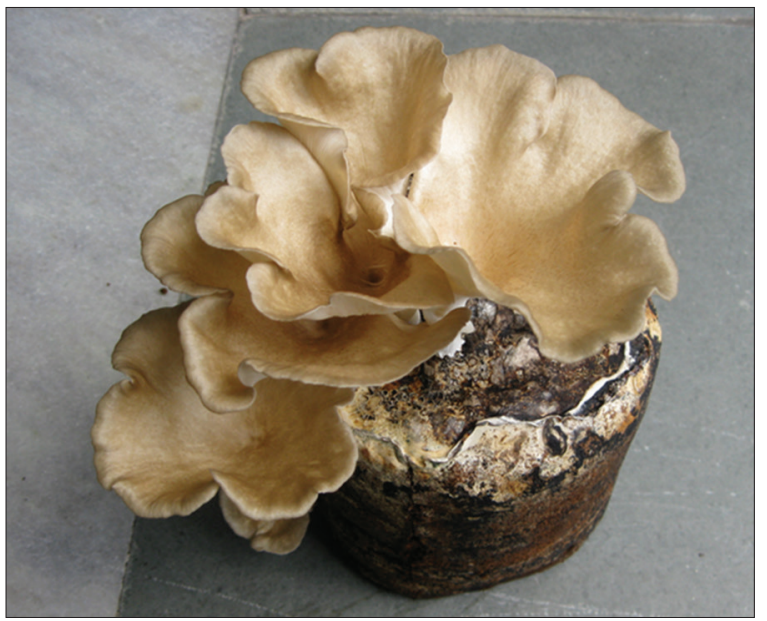

Fig 5b. Fully developed fruit bodies.

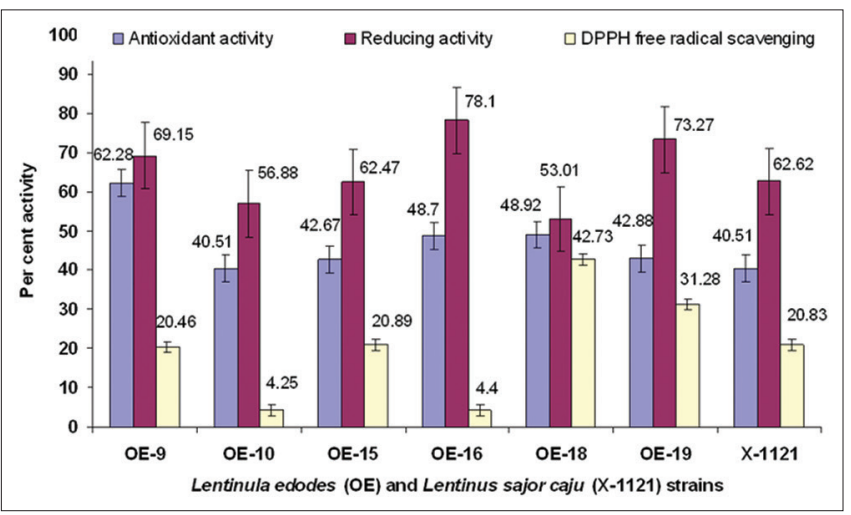

Fig 6. Neutraceutical properties of Lentinus sajor-caju strain (X-1121) vis-à-vis other cultivated Lentinula edodes strains (OE-9 to OE-19) when cultivated on saw dust.

morphological descriptions and comparisons were done. It is confirmed that L. sajor-caju should not be placed in Pleurotus. The most important distinction between Lentinus and Pleurotus is the hyphal system forming the basidioma. L. sajor-caju has dimitic myceliual system having both generative and skeleto-ligative hyphae whilst $P$. ostreatus is monomitic having only generative hyphae (Peglar and Yao, 1995). Both morphological and molecular data were gathered from strains of the same fungus. The absence of the annulus on the stipe and of the hyphal pegs on the hymenophoral trama, coupled with the larger basidiospores (7.0 - $10.5 \times 3.0-4.5 \mu \mathrm{m})$, distinguish P. sajor-caju from L. sajor-caju (Li and Yao, 2005). Strains of this mushroom share a very similar or identical ITS sequence with other collections from the field, which is different from those of P. ostreatus and P. sajor caju, a morphologically close related species (Li and Yao, 2005). Data were combined with ITS sequences from 11 related strains, including Pleurotus, Lentinus, Lentinula, Cordyceps and Ophiocordyceps, obtained from GenBank to construct a phylogenetic tree using the Neighbor-joining method with Cordyceps militaris and Ophiocordyceps sinensis as the outgroups. The P. sajor-caju test strain was located on a branch that incorporated all the other Pleurotus strains examined with a shared similarity value $>98.5 \%$. Similarity values among Lentinus and Lentinula strains were also $>98 \%$, but only $80 \%$ when all three genera were compared (Huang et al., 2009).

The BLAST analysis of the ITS-5.8S rDNA sequences showed almost $99 \%$ similarity with the available sequences of $L$. sajor-caju with an expect value of 0.0 which showed high similarity between the sequences and indicated that the specimen belong to the same species. Besides, the line drawing and morphological data coupled with the molecular data confirmed the identity of the specimen. The Phylogenetic analysis using fast minimum evolution method also showed that the specimen showed varied identities with Lentinus and Polyporus species and Pleurotus was not even close to it.

Very few studies have been taken up on development of cultivation technology of L. sajor-caju. Commercial/ medicinal utility of this species needs to be further explored. The shiitake mushroom ( $L$. edodes) is a temperate mushroom and cultivated at a low temperature of $14-18^{\circ} \mathrm{C}$ while Lentinus sajor-caju species is a tropical mushroom and optimum fruiting temperature is $28-30^{\circ} \mathrm{C}$, which offers a vast scope of commercial cultivation in a country like India.

The nutritional analysis of the cultivated and reported nutrient values of wild L. sajor-caju fruit bodies was compared and it was found that cultivated fruit bodies had better nutritional values than the wild one (Gulati et al., 2011). While Singdevsachan et al. (2013) has reported higher protein contents in wild L. sajor-caju strain from Odisha (India). This difference in protein values may due to the difference in geographical conditions of Andaman \& Nicobar and Odisha. The antioxidant, reducing and $\mathrm{DPPH}$ free radical scavenging properties of the cultivated 
L. sajor-caju fruit bodies were assayed during this study and it was observed that the cultivated L. sajor-caju strain had fairly good biological activities. Singdevsachan et al. (2013) also studied the biological activity of wild $L$. sajor-caju strain and reported a total of all the types of activity to the tune of $70.54 \%$ which included antioxidant property, DPPH scavenging activity, $\mathrm{H}_{2} \mathrm{O}_{2}$ and metal chelating activity.

\section{Author contributions}

M. S. collected the sample and planned the study. The taxonomic studies were done by R. C. U. and S. K. S. V.P. S. has done culturing, cultivation experiments and Molecular work. S. K. has done the nutritional and nutraceutical analysis of the sample. S. K. has done the molecular work, phylogenetic analysis and compiled and concluded the work.

\section{REFERENCES}

Corner, E. J. H. 1981. The agaric genera Lentinus, Panus, and Pleurotus with particular reference to Malaysian species. Nova. Hedwig. Beih. 69: 1-169.

Gulati, A., N. S. Atri, S. K. Sharma and B. M. Sharma. 2011. Nutritional studies of five wild Lentinus species from North India. World J. Dairy and Fd. Sci. 6(2): 140-145.

Hatano, T., H. Kagawa, T. Yasuhara and T. Okuda. 1988. Two new flavonoids and other constituents in licorice root: their relative astringency and radical scavenging effects. Chem. Pharm. Bull. 36: 2090-2097.
Huang, L., Qingping Wu, Xiaobing Yang and Jume Zhang. 2009. Taxonomic Status of Pleurotus sajor-caju cultivated in China Based on ITS Sequence Analysis. Acta. Edulis. Fungi. 16(02): 34-39.

Kühner, R. 1980. Les Hyménomycètes agaricoïdes. Bull. Soc. Linn. Lyon. 49:1027.

Li, X. L. and Y. J. Yao. 2005. Revision of the taxonomic position of the Phoenix Mushroom. Mycotaxon. 91: 61-73.

Miller, O. 1973. Mushrooms of North America. Dutton, New York.

Oyaizu, M. 1986. Studies on product of browning reaction prepared from glucose amine. Jpn. J. Nutr. 44: 307-315.

Pegler, D. N. 1975. The classification of the genus Lentinus Fr. (Basidiomycota). Kavaka. 3: 11-20.

Pegler, D. N. 1983. The genus Lentinus: a world monograph. HMSO, London.

Pegler, D. N. and Y. J. Yao. 1995. The distinction between Lentinus sajor-caju and Pleurotus ostreatus and their taxonomy. Acta. Bot. Yunnan. 17: 305-311.

Singdevsachan, S. K., J. K. Patra and H. Thatoi. 2013. Nutritional and bioactive potential of two wild edible mushrooms (Lentinus sajorcaju and Lentinus torulosus) from Similipal Biosphere Reserve, India. Food. Sci. Biotechnol. 22(1): 137-145.

Singer, R. 1986. The Agaricales in modern taxonomy, 4th edn. Koeltz, Koenigstein, Germany.

Thompson, J. D., T. J. Gibson, F. Plewniak, F. Jeanmougin and D. G. Higgins. 1997. The Clustal X windows interface: flexible strategies for multiple sequence alignment aided by quality analysis tools. Nucleic. Acid. Res. 24: 4876-4882.

White, T. J., T. Bruns, S. Lee and J. W. Taylor. 1990. Amplification and direct sequencing of fungal ribosomal RNA genes for phylogenetics. In: PCR protocols: a guide to methods and applications (Innis, M.A., D.H. Gelfand, J. J. Sninsky, T. J. White, editors, Academic, New York, pp 315-322. 